\title{
Main Contributory Factors on Asthma Control and Health-Related Quality of Life in Elderly Asthmatics
}

\author{
Enríquez-Matas $\mathrm{A}^{1 *}$, Fernández-Rodríguez $\mathrm{C}^{1 *}$, Andrés Esteban $\mathrm{EM}^{2}$, Fernández-Crespo J11 \\ 'Servicio de Alergia, Hospital 12 de Octubre, Instituto de Investigación Hospital 12 de Octubre (i+12), Madrid, Spain \\ ${ }^{2}$ Instituto de Investigación Sanitaria, Unidad de Investigación Clínica, Hospital Universitario 12 de Octubre, Madrid, Spain \\ *Both authors contributed equally to this work.
}

J Investig Allergol Clin Immunol 2020; Vol. 30(4): 264-271

doi: 10.18176/jiaci.0430

\begin{abstract}
Objective: To assess the main factors involved in asthma control and health-related quality of life in elderly asthmatic patients. Methods: We performed a retrospective case-control study nested in a historical cohort that compared patients who had partly controlled or uncontrolled asthma (Asthma Control Test $[A C T]$ score $\leq 19$ ) (cases) with patients who had well-controlled asthma (ACT $\geq 20)$ (controls). Clinical data were collected from medical records. Outcomes included ACT score and health-related quality of life (Asthma-Specific Quality of Life Questionnaire [AQLQ]). Pulmonary function was determined by spirometry.

Results: We evaluated 209 asthma patients (151 women) aged $\geq 65$ years. Mean age was 73.55 years. Most patients had persistent moderate $(47.60 \%)$ or severe $(47.12 \%)$ asthma. A total ACT score $\leq 19$ was obtained in $64(30.62 \%)$ patients. Lack of adherence to treatment and presence of severe exacerbations were risk factors for partly controlled/uncontrolled asthma (OR, 8.33 and 5.29, respectively). In addition, for each additional unit score in the AQLQ, the risk of poor control increased by 1.51. The factors influencing the AQLQ score were asthma control (ACT) and presence of comorbidities such as depression, gastroesophageal reflux disease, and osteoporosis.

Conclusions: Despite receiving antiasthma therapy, almost one-third of elderly patients had uncontrolled asthma, possibly as a result of poor adherence, exacerbations, and reduced health-related quality of life. Nonrespiratory comorbid conditions in older patients do not seem to be associated with worse control of asthma symptoms, although their effect on health-related quality of life could indirectly affect asthma control.
\end{abstract}

Key words: Elderly asthma. Asthma control. ACT. Comorbidity. Health-related quality of life. AQLQ. Treatment adherence.

\section{Resumen}

Objetivo: Evaluar los principales factores que contribuyen al control del asma y la calidad de vida relacionada con la salud en personas asmáticas de edad avanzada.

Métodos: Estudio retrospectivo de casos y controles anidado en una cohorte histórica que comparó pacientes con asma mal o parcialmente controlada (ACT $\leq 19$ ) (casos) con pacientes que tenían buen control del asma ( $A C T \geq 20)$ (controles). Los datos relativos a las características clínicas se obtuvieron de las historias clínicas. Los resultados incluyeron los resultados del ACT (test de control de asma) y AQLQ (cuestionario de calidad de vida específica de asma). La función pulmonar se determinó mediante espirometría.

Resultados: Se evaluaron 209 pacientes (151 mujeres) $\geq 65$ años con asma. La edad media fue de 73,55 años. La mayoría de los pacientes tenían asma persistente moderada (47,60\%) o grave (47,12\%). Se obtuvo una puntuación total de ACT $\leq 19$ en 64 pacientes (30,62\%). La falta de adherencia al tratamiento y la presencia de exacerbaciones graves se comportaron como un factor de riesgo para el asma parcialmente o mal controlada (OR 8,33 y OR 5,29, respectivamente). Además, por cada unidad de mayor puntuación en el AQLQ, el riesgo de un control deficiente aumentó 1,51. Los factores que influyeron en el AQLQ fueron el control del asma (ACT) y la presencia de comorbilidades como depresión, ERGE y osteoporosis.

Conclusiones: A pesar de haber recibido tratamiento antiasmático, casi un tercio de los pacientes de edad avanzada tenía asma no controlada. Se debe tener en cuenta factores relacionados con la adherencia al tratamiento, las exacerbaciones y la calidad de vida relacionada con la salud. Las afecciones comórbidas no respiratorias en pacientes de edad avanzada no parecen estar asociadas con un peor control de los síntomas del asma, pero su influencia en la calidad de vida relacionada con la salud podría afectar indirectamente el control del asma.

Palabras clave: Asma en edad avanzada. Control de asma. ACT. Comorbilidad. Calidad de vida relacionada con la salud. AQLQ. Adherencia a tratamiento. 


\section{Introduction}

Asthma is a complex chronic disease affecting patients of all ages. In the elderly, it is frequently underdiagnosed and undertreated, thus affecting asthma morbidity and mortality rates in this population [1-3]. Treatment is often suboptimal in elderly patients owing to underassessment of asthma control/severity by clinicians [1]. In addition, multiple patient factors may lead to suboptimal disease control, including misunderstanding of asthma as a disease and the treatment regimen, poor adherence, comorbidities, decreased cognitive or physical capabilities, and socioeconomic challenges [3-6]. Although comorbidity and polypharmacy are considered to be major reasons for poorer control of asthma in older adults, no conclusive evidence exists to support these assumptions [7] and little is known about the co-occurrence of multiple chronic diseases with asthma in the elderly.

Comorbidities have an impact on the course of asthma and affect patients' quality of life (QOL) [8,9]. QOL is impaired in elderly people with a diagnosis of asthma $[2,9,10]$. The impairment may be influenced by age, asthma severity, duration of illness, socioeconomic conditions, somatic comorbidities, and the presence of psychological factors such as anxiety and depression [2,9-15]. In recent years, there has been increased interest in the subjective QOL of patients with bronchial asthma. QOL is a significant indicator for guiding the efforts of professionals caring for patients, especially chronically ill ones. The identification of factors affecting patient-reported QOL - irrespective of their existing condition - is important and useful when attempting to provide multidisciplinary care. However, the patient's perspective about asthma and its treatment in specific populations such as the elderly have received little attention [16].

The aim of our study was to assess the main factors contributing to asthma control and health-related QOL (HRQOL) in elderly persons.

\section{Methods}

\section{Study Subjects and Collection of Data}

We performed a retrospective case-control study nested in a historical cohort. We compared patients who had partly controlled or uncontrolled asthma (Asthma Control Test [ACT] $\leq 19$ ) (cases) with patients who had controlled asthma (ACT $\geq 20$ ) (controls).

We included 209 consecutive patients aged $\geq 65$ years and diagnosed with asthma in the Allergy Department of Hospital Universitario 12 de Octubre, Madrid, Spain. The diagnosis was supported by a compatible clinical history (dyspnea, chest tightness, coughing, and wheezing) and the positive outcome of an objective diagnostic test (on enrolment or based on historical data in the medical record). The tests included spirometry with reversibility testing, defined as at least $12 \%$ and a $200-\mathrm{mL}$ increase in forced expiratory volume in 1 second $\left(\mathrm{FEV}_{1}\right)$ from baseline, diagnostic methacholine challenge, or historical data of reversibility of $\mathrm{FEV}_{1}$ after oral corticosteroid trial and/or diffusion test in a patient with persistent $\mathrm{FEV}_{1} /$ forced vital capacity $(\mathrm{FVC})<70$ and/or $\mathrm{FEV}_{1}<80 \%$. Current smokers were excluded. Patients unable to perform spirometry or with no recent lung function data were not included in the study.

The study protocol was reviewed and approved by the Ethics Committee of Hospital Universitario 12 de Octubre, Madrid (CEIC 14/175).

\section{Assessments}

We collected self-reported age at onset of asthma, disease duration, severe asthma exacerbations in the previous year (defined as asthma exacerbations requiring an emergency department visit and/or hospitalization), and comorbidities. Height and weight data were collected from medical records, and body mass index (BMI) was defined as weight divided by height squared, with obesity considered a BMI $\geq 30$.

Treatments received for longstanding asthma (short-acting $\beta_{2}$-agonists, inhaled corticosteroids, long-acting $\beta_{2}$-agonists, combinations, and other treatments) were recorded. The daily dosage of inhaled corticosteroid was expressed as low, medium, or high according to the GINA 2006 classification [17]. Adherence to treatment (self-reported) and inhalation technique (evaluated by the doctor) were collected from the clinical history. Atopy was assessed (at enrolment or based on data from the clinical history) by skin prick testing to a panel of common aeroallergens including pollens, molds, house dust mite, and pet dander. A positive skin prick test was defined as a wheal at least $3 \mathrm{~mm}$ larger than the diameter of the negative control. Asthma severity was classified following the GINA 2006 criteria based on frequency of symptoms, night-time awakenings, use of short-acting $\beta_{2}$-agonists, interference with normal activity, and lung function for patients who were not taking long-term control medications on enrolment or determined by the lowest level of treatment required to maintain control in those taking long-term control medication [17].

Pulmonary function was assessed using spirometry as a part of routine medical assessment according to the standardized technique [18]. Parameters of lung function such as FVC, $\mathrm{FEV}_{1}$, and $\mathrm{FEV}_{1} / \mathrm{FVC}$ in 2009 (baseline spirometry) were obtained using a Jaeger Pneumotach device (Viasys Healthcare GmbH). Clinical control status in 2009 was evaluated using the validated Spanish version [19] of the ACT [20], and HRQOL was evaluated using a validated Spanish version [21] of the Asthma-Specific Quality of Life Questionnaire (AQLQ) of Marks et al [22].

Inhaler technique was checked by the doctor/nurse as a part of routine medical check-up.

\section{Assessment Scales}

The ACT [20] is designed to measure asthma control without using pulmonary function values. The cut-off points are $\geq 20$ for well-controlled asthma, 16-19 for partly controlled asthma, $\leq 15$ for uncontrolled asthma [17].

The AQLQ of Marks et al [22] is a 20-item selfadministered questionnaire, which covers 4 dimensions (breathlessness, mood, social limitation, and worrying) and gives a total score and subscale scores. Patients have to respond to a series of statements describing the way in which asthma (or its treatment) affects them and indicate which option most applies to them over the previous 4 weeks. A score of 10 
corresponds to maximum impairment of quality of life and a score of 0 corresponds to no impairment.

\section{Statistical Analysis}

Descriptive bivariate and multivariate analyses were conducted in order to identify factors associated with asthma control and asthma-related QOL.

Data are expressed as mean (SD), percentage, and 95\%CI, where appropriate. The $\chi^{2}$ test (with a contingency table), Mann-Whitney test, or $t$ test was used to compare 2 groups. The Kruskal-Wallis and ANOVA test were used for more than 2 independent groups with a nonnormal and normal distribution, respectively. Correlations between variables were calculated using the Spearman coefficient or Pearson $\mathrm{R}^{2}$.

Multivariate analysis was performed using multiple linear regression for the AQLQ (total score and domain scores) as dependent variables. Logistic regression was used when poor control of asthma was analyzed as a dichotomous variable with the independent variables being all those that were statistically significant in the bivariate analysis or whose clinical implication was plausible. The results of the multivariable model were presented as the coefficient, $\mathrm{SD}$, and $P$ value. Statistical significance was set at $P<.05$.
The statistical tests were performed using Stata Data Analysis and Statistical Software (Version 10, StataCorp LP).

\section{Results}

\section{Characteristics of the Study Population}

We successfully evaluated 209 asthmatic patients (149 women and 60 men) aged $\geq 65$ years. In the population studied, asthma was more common in women, mainly with an intrinsic profile (nonallergic) and generally as long-standing disease, with onset in middle age. The mean (SD) age of participants was 73.55 (5.44) years, and $20.57 \%(n=43)$ were former smokers (at least 1 year). The mean age at onset of asthma was 46.76 (15.76) years. Mean age at onset of asthma was 43.51 (14.68) years in men and 48.08 (16.05) years in women $(P=.048)$. Long-standing asthma with onset before 65 years of age was recorded in 180 patients $(87.98 \%)$ and late-onset asthma (over 65 years of age) in 25 patients $(12.02 \%)$. There were more women in the late-onset asthma group $(P=.014)$.

According to the GINA 2006 classification, most patients had persistent-moderate asthma (99 patients; $47.37 \%$ ) or severe asthma (98 patients; $46.89 \%$ ). During the preceding

Table 1. Demographic, Clinical, and Functional Data

\begin{tabular}{|c|c|c|c|}
\hline \multirow{2}{*}{$\begin{array}{l}\mathrm{N}=209 \\
\text { Male/Female }\end{array}$} & \multicolumn{2}{|c|}{ No. $(\%)$ or Mean $(\mathrm{SD})$} & \multirow[t]{2}{*}{ No. $(\%)$} \\
\hline & $60 / 149(28.7 / 71.3)$ & Degree of asthma severity & \\
\hline Age, y & $73.55(5.44)$ & Intermittent & $3(1.44)$ \\
\hline Duration of disease & $26.77(15.38)$ & Mild-persistent & $7(3.35)$ \\
\hline Atopy & $70(33.49)$ & Moderate-persistent & $99(47.37)$ \\
\hline Comorbidity & & Severe-persistent & $98(46.89)$ \\
\hline Obesity $(\mathrm{BMI} \geq 30)$ & $84(40.19)$ & Not known & $2(0.96)$ \\
\hline Hypertension & $124(59.33)$ & Prescribed treatment $(\%)$ & \\
\hline Hypercholesterolemia & $57(27.27)$ & Inhaled corticosteroids-LABA & $189(90.43)$ \\
\hline Ischemic cardiomyopathy & $21(10.05)$ & Leukotriene modifiers & $80(38.28)$ \\
\hline Heart arrhythmias & $22(10.53)$ & Anticholinergics & $36(17.22)$ \\
\hline Thyroid disease & $28(13.40)$ & Inhaled corticosteroid dose & \\
\hline Other cardiovascular disease $\mathrm{a}^{\mathrm{a}}$ & $30(14.35)$ & Low & $35(17.16)$ \\
\hline Glaucoma & $21(10.05)$ & Medium & $71(34.80)$ \\
\hline Arthrosis & $148(70.81)$ & High & $98(48.04)$ \\
\hline Osteoporosis & $95(45.45)$ & Pulmonary function & \\
\hline Obstructive sleep apnea & $7(3.35)$ & $\mathrm{FEV}_{1} / \mathrm{FVC}(\%)$ & \\
\hline Other respiratory diseases ${ }^{\mathrm{b}}$ & $35(16.75)$ & $\geq 70$ & $135(64.59)$ \\
\hline Rhinitis & $139(66.51)$ & $<70$ & $74(35.41)$ \\
\hline Sinonasal polyposis & $50(23.92)$ & $\mathrm{FEV}_{1}(\%)$ & \\
\hline Gastroesophageal reflux & $101(48.33)$ & $<60$ & $9(4.31)$ \\
\hline Depression & $61(29.19)$ & $60-80$ & $54(25.84)$ \\
\hline \multirow[t]{2}{*}{ AERD } & $23(11.00)$ & $>80$ & $146(69.86)$ \\
\hline & & Severe exacerbations & $23(11.00)$ \\
\hline
\end{tabular}

aHeart failure, structural heart diseases.

${ }^{b}$ History of tuberculosis, bronchiectasis, or pulmonary embolism.

Abbreviations: AERD, aspirin-exacerbated respiratory disease; BMI, body mass index; LABA, long-acting $B_{2}$-agonists. 
year, 23 patients $(11 \%)$ had severe exacerbations requiring at least 1 emergency department visit and/or hospitalization. As for adherence, $92.34 \%$ reported taking the treatment prescribed by their doctors. Most patients experienced comorbidities, with a median of 4 coexisting conditions. Acceptable spirometry values were collected in all patients. Most patients (69.68\%, 146 patients) had an $\mathrm{FEV}_{1}>80 \%$ predicted, 25.84\% (54 patients) had an $\mathrm{FEV}_{1}$ of $60 \%-80 \%$ predicted, and $4.31 \%$ (9 patients) had an $\mathrm{FEV}_{1}<60 \%$ predicted.
In patients with persistent obstruction (defined as $\mathrm{FEV}_{1} / \mathrm{FVC}$ $<70 \%$ and/or $\mathrm{FEV}_{1}<80 \%$ according to their clinical history $[n=24]$ ), diffusion test results were normal in 14 (of whom 6 were ex-smokers); the remaining patients had an unequivocal history of long-standing asthma (allergic asthma or aspirinexacerbated respiratory disease [AERD] with documented variability in $\mathrm{FEV}_{1}$ ).

Demographic, clinical, and functional data are summarized in Table 1.

Table 2. Asthma Control and Factors Affecting Asthma Control

\begin{tabular}{|c|c|c|c|c|c|c|c|}
\hline & \multicolumn{2}{|c|}{ Level of Asthma Control } & \multirow{2}{*}{$\begin{array}{c}P \\
\text { Value }\end{array}$} & & \multicolumn{2}{|c|}{ Level of Asthma Control } & \multirow{2}{*}{$\begin{array}{c}P \\
\text { Value }\end{array}$} \\
\hline & $\begin{array}{c}\mathrm{ACT} \leq 19 \\
(\mathrm{n}=64)\end{array}$ & $\begin{array}{c}\mathrm{ACT} \geq 20 \\
(\mathrm{n}=145)\end{array}$ & & & $\begin{array}{c}\mathrm{ACT} \leq 19 \\
(\mathrm{n}=64)\end{array}$ & $\begin{array}{c}\mathrm{ACT} \geq 20 \\
(\mathrm{n}=145)\end{array}$ & \\
\hline Gender & & & .001 & Atopy & & & .648 \\
\hline Male & $8(12.50)$ & $52(35.86)$ & & Atopic asthma & $20(31.25)$ & $50(34.48)$ & \\
\hline Female & $56(87.50)$ & $93(64.14)$ & & Nonatopic asthma & $44(68.75)$ & $95(65.52)$ & \\
\hline Age, y & & & .821 & $\mathrm{FEV}_{1} / \mathrm{FVC}, \%$ & & & .602 \\
\hline$<75$ & $36(56.25)$ & $84(57.93)$ & & $\geq 70$ & 43 (67.19) & $92(63.45)$ & \\
\hline$\geq 75$ & $28(43.75)$ & $61(42.07)$ & & $<70$ & $21(32.81)$ & $53(36.55)$ & \\
\hline Duration of disease $^{\mathrm{a}}$ & $27.51(16.01)$ & $26.45(15.14)$ & .572 & $\mathrm{FEV}_{1}(\%)$ & & & .165 \\
\hline Degree of asthma severity & & & .305 & $<60$ & $3(4.69)$ & $6(4.14)$ & \\
\hline Intermittent & $0(0.00)$ & $3(2.07)$ & & $60-80$ & $11(17.19)$ & $43(29.66)$ & \\
\hline Mild-persistent & $2(3.13)$ & $5(3.45)$ & & $>80$ & $52(78.13)$ & $96(66.21)$ & \\
\hline Moderate-persistent & $26(40.63)$ & $73(50.34)$ & & Treatment & & & \\
\hline Severe-persistent & $36(56.25)$ & $62(42.76)$ & & Inhaled corticosteroids-LABA & $60(93.75)$ & $129(88.97)$ & .278 \\
\hline Unknown & $0(0.00)$ & $2(1.38)$ & & Leukotriene modifiers & $26(40.63)$ & $54(37.24)$ & .643 \\
\hline Comorbidity & & & & Anticholinergics & $18(28.13)$ & $18(12.41)$ & .006 \\
\hline Obesity & $26(40.63)$ & $58(40.00)$ & .932 & Inhaled corticosteroid dose & & & .102 \\
\hline Hypertension & $41(64.06)$ & $83(57.24)$ & .355 & Low & $10(15.87)$ & $25(17.73)$ & \\
\hline Hypercholesterolemia & $13(20.31)$ & $44(30.34)$ & .133 & Medium & $16(25.40)$ & $55(39.01)$ & \\
\hline Ischemic cardiomyopathy & y $5(7.81)$ & $16(11.03)$ & .475 & High & $37(58.73)$ & $61(43.26)$ & \\
\hline Heart arrythmias & $6(9.38)$ & $16(11.03)$ & .719 & Severe exacerbations & & & .000 \\
\hline Thyroid disease & $11(17.19)$ & $17(11.72)$ & .285 & No & $49(76.56)$ & $137(94.48)$ & \\
\hline $\begin{array}{l}\text { Other cardiovascular } \\
\text { diseases }^{\mathrm{a}}\end{array}$ & $14(21.87)$ & $16(11,08)$ & .411 & Yes & $15(23.44)$ & $8(5.52)$ & \\
\hline Glaucoma & $8(12.50)$ & $13(8.97)$ & .433 & Treatment adherence & & & .021 \\
\hline Arthrosis & $47(73.44)$ & $101(69.66)$ & .579 & No & $9(14.06)$ & $7(4.83)$ & \\
\hline Osteoporosis & $32(50.00)$ & $63(4 ., 45)$ & .381 & Yes & $55(85.94)$ & $138(95.17)$ & \\
\hline Obstructive sleep apnea & $2(3.13)$ & $5(3.45)$ & .905 & Quality of life questionnaire s & $\mathrm{re}^{\mathrm{a}}$ & & \\
\hline Other respiratory diseases ${ }^{\mathrm{b}}$ & $s^{b} 8(12,12)$ & $18(12.41)$ & .474 & Mood & $5.07(2.49)$ & $2.56(2.37)$ & .000 \\
\hline Rhinitis & $46(71.88)$ & $93(64.14)$ & .275 & Breathlessness & $3.93(2.18)$ & $1.01(1.32)$ & .000 \\
\hline Sinonasal polyposis & $12(18.75)$ & $38(26.21)$ & .244 & Worrying & $3.34(2.13)$ & $1.27(1.59)$ & .000 \\
\hline Gastroesophageal reflux & x $32(50.00)$ & $69(47.59)$ & .748 & Social limitation & $3.19(2.60)$ & $0.98(1.69)$ & .000 \\
\hline Depression & $22(34.88)$ & $39(26.90)$ & .273 & Total & $3.87(1.82)$ & $1.44(1.34)$ & .000 \\
\hline AERD & $4(6.25)$ & $19(13.10)$ & .144 & & & & \\
\hline
\end{tabular}

aMean and standard deviation

bHistory of TBC infection, bronchiectasis, pulmonary embolism.

Abbreviations: ACT, Asthma Control Test; AERD, aspirin-exacerbated respiratory disease; LABA, long-acting $B_{2}$-agonist. 


\section{Asthma Control and Factors Affecting Asthma Control}

A total of 145 patients $(69 \%)$ had an ACT score $\geq 20$ (well-controlled), 35 patients $(16 \%)$ had a score of 16-19 (partly controlled), and 29 patients (13\%) had a score of $\leq 15$ (uncontrolled). According to the ACT score, we classified patients into 2 groups (cases and controls), where cases had partly controlled/uncontrolled asthma (ACT $\leq 19,64$ patients, $30.62 \%$ ) and controls had well-controlled asthma (ACT $\geq 20,145$ patients, $69.38 \%$ ). We reported the main variables by level of asthma control (Table 2). When we analyzed comparisons between groups, we did not find any statistically significant differences as a function of age, atopy, disease duration, lung function, asthma severity, AERD, or comorbid conditions. We did find, however, significantly poorer asthma control in women. The percentage of patients reporting severe exacerbations in the year before the visit was lower in patients with controlled asthma than in those

Table 3. Statistical Analysis of the Predictors of Asthma Control

\begin{tabular}{lccc}
\hline & OR & $P$ Value & $95 \% \mathrm{CI}$ \\
\hline No treatment adherence & 8.33 & .002 & $2.22-30.30$ \\
AQLQ Total score & 1.58 & .024 & $1.06-2.23$ \\
Breathlessness subscale & & & \\
AQLQ score & 1.82 & .001 & $1.28-2.59$ \\
Severe exacerbations & 5.29 & .006 & $1.60-17.52$ \\
\hline
\end{tabular}

Abbreviation: AQLQ, Asthma-Specific Quality of Life Questionnaire.

Table 4. Multiple Regression Analysis of AQLQ Total Score in Relation to Selected Variables

\begin{tabular}{|c|c|c|c|}
\hline Variable & $\begin{array}{l}\text { AQLQ Total Score } \\
\text { Coefficient }\end{array}$ & SE & $P$ Value \\
\hline \multicolumn{4}{|l|}{ Gender } \\
\hline Male & ref & & .351 \\
\hline Female & .24 & .26 & \\
\hline \multicolumn{3}{|l|}{ Osteoporosis } & .021 \\
\hline No & ref & & \\
\hline Yes & .52 & .22 & \\
\hline \multicolumn{3}{|l|}{ GERD } & .026 \\
\hline No & ref & & \\
\hline Yes & .47 & .21 & \\
\hline \multicolumn{3}{|l|}{ Depression } & .000 \\
\hline No & ref & & \\
\hline Yes & .99 & .22 & \\
\hline \multicolumn{3}{|l|}{ ACT score } & .000 \\
\hline$\leq 19$ & ref & & \\
\hline$\geq 20$ & 2.28 & .22 & \\
\hline \multicolumn{3}{|c|}{ Severe exacerbations } & .867 \\
\hline No & ref & & \\
\hline Yes & -.05 & .33 & \\
\hline
\end{tabular}

with partly/uncontrolled asthma $(P<.001)$. The number of comorbidities was not associated with asthma control status $(P=.448)$. Patients with AERD did not have more severe asthma according to the GINA 2006 classification $(P=.380)$.

Given that adherence was associated with asthma control $(P=.021)$, correct adherence was more frequent in the well-controlled group. Anticholinergic treatment was more frequently prescribed in patients with partly/ uncontrolled asthma $(P=.006)$. No patients were taking specific immunotherapy at the time of the study, although $42(20.1 \%)$ had previously received subcutaneous immunotherapy (when they were young or middle-aged); however, this was not analyzed because of the marked heterogeneity of the treatments. No patients were receiving biologic treatment.

In the AQLQ score (domains and total), patients with partly controlled/uncontrolled disease tended to score higher (ie, greater impairment in quality of life).

In the multivariate analysis of factors affecting asthma control measured using the ACT (Table 3), lack of adherence to treatment and the presence of severe exacerbations behaved as risk factors for partly controlled/uncontrolled asthma (OR, 8.33 and 5.29, respectively). In addition, for each extra unit in the AQLQ (total score or dyspnea subscale), the risk of poor control increased 1.51 and 1.88 times, respectively.

Multiple linear regression was performed using the AQLQ total score and subscales as the dependent variable and selected variables (those with clinical implication or associated with AQLQ in the bivariate analysis) as independent variables. The analysis revealed that worse quality of life (total score) was predicted by depression, gastroesophageal reflux disease, osteoporosis, and asthma control (evaluated using the ACT score) (Table 4).

\section{Discussion}

Suboptimal control of asthma has been reported in several studies [23-25]. According to the ACT score, in Spain, uncontrolled asthma could affect up to $57.6 \%$ of patients [26]. The LIAISON study, which is one of the largest observational studies on the characteristics and management of asthmatics in Europe and is based on patient-reported outcomes and the Asthma Control Questionnaire (ACQ), confirmed rates of suboptimal control in $56.5 \%$ of patients [27].

Studies evaluating asthma control in the elderly are scarce, although they agree that one-third or more of elderly asthmatic patients have uncontrolled asthma. Milanese et al [28] performed a multicenter observational study analyzing a total of 350 patients aged more than 64 years with documented physician-diagnosed asthma in Italy and found that $39 \%$ had an ACT score $\leq 19$ [28]. Rates of uncontrolled asthma were similar in Korea [29] and Romania [30] (35.2\% and 30.15\%, respectively). Our findings also indicate that asthma control was suboptimal in one-third of older outpatients with asthma in a real-life study. This percentage is lower than that observed in other age groups, probably because the patients were receiving ongoing asthma treatment and being followed-up at a tertiary care academic hospital for at least 1 year.

Comorbidities have been associated with poorly controlled asthma $[4,30]$, and it is well known that older patients with 
asthma have an increased risk of comorbidities. Particularly frequent comorbidities, such as chronic obstructive pulmonary disease, chronic sinusitis, obesity, and depression are associated with uncontrolled asthma in elderly asthmatic patients [31]. Furthermore, the number of comorbidities and polypharmacy have been linked with asthma control in the elderly [32,33]. However, recent studies demonstrated that in elderly asthmatics under specialist care, nonrespiratory comorbidities do not seem to have a direct negative effect on asthma control according to Global Initiative for Asthma criteria [34] or according to the ACT score [28-30,33]. Our results are similar, since none of the evaluated diseases per se or the number of comorbidities were associated with poor asthma control.

Milanese et al [28] found that the coexistence of chronic obstructive pulmonary disease (COPD) or asthma-COPD overlap syndrome (ACOS) due to the presence of chronic bronchitis and/or lung diffusion impairment had lower mean ACT scores. Persistent airway obstruction and mixed ventilator dysfunction were also associated with poor asthma control in the elderly [30]. In general, diagnosis of asthma in the elderly is particularly challenging as a result of spirometry changes associated with aging and the similar clinical presentation of asthma, COPD, and ACOS [1]. In an attempt to exclude COPD patients, we excluded current smokers and those with persistent fixed airflow obstruction and no normal diffusion test result or an unequivocal asthma history at the initial diagnosis. Therefore, we could not evaluate the influence of this comorbidity on the ACT score, although lung function did not modify the score in our study.

Previous findings showed that both a previous history of asthma exacerbations and poor asthma control can increase the risk of future asthma exacerbations $[35,36]$. In addition, poorly or partly controlled asthma in elderly patients has been characterized by higher exacerbation rates [28-30], and an ACT score $<19$ may be a significant predictor of asthma exacerbation in the following 6 months [33]. Our results also revealed an association between severe exacerbations in the previous year and partly controlled/uncontrolled asthma in the previous 4 weeks $(\mathrm{OR}, 5.29)$, thus indicating that the ACT control test may be an important parameter for assessing the risk of asthma exacerbations and consumption health care resources in elderly asthmatic patients.

Good adherence is a predictor of asthma control in adults in general [37] and in the elderly in particular [15]. In this respect, we found lack of adherence to be a predictor of poor asthma control (OR, 8.33). However, we based our analysis of adherence on self-reported data, which were probably not an accurate measure, whereas other authors also reported high rates of adherence to asthma treatment in the elderly using more accurate measures of adherence [33].

In our study, asthma control and QOL were directly related. Although comorbidities were not determinants of asthma control, the presence of some comorbidities such as depression, gastroesophageal reflux disease, and osteoporosis were found to be associated with QOL. A significant reduction in QOL associated with comorbidity in asthma has been reported [8,15].

In contrast with data reported by other authors [38], we did not detect a relationship between QOL and exacerbations, probably because of the methodology used: exacerbations were collected during the previous year, whereas the QOL questionnaire of Marks et al [22] analyzes data from the previous 4 weeks.

Furthermore, patient-perceived QOL directly affects the degree of control according to the ACT questionnaire, as reported elsewhere [27]. In our opinion, the information contributed by both questionnaires is complementary, and in patients of this age group it can help with decisions on therapy and in cases where depression is suspected. This is very important, as depression is not only correlated with asthma control and QOL, but is also a predictor of future exacerbations, thus highlighting the need for depression screening and evaluation in the elderly [39].

To the best of the authors' knowledge, this is the first study in elderly persons with asthma to report the main determinants of asthma control and HRQOL in the Spanish population.

Our study is subject to methodological limitations. First, patients were recruited from a tertiary hospital, which is likely to result in a group with relatively severe asthma and frequent comorbidity. Second, patients did not undergo a complete psychological examination, and we did not use a specific geriatric assessment scale to determine depression and functional status. And third, adherence was not evaluated with an objective medication adherence measure or validated test.

In conclusion, most elderly asthmatic patients, even those with severe or moderate persistent asthma, those with comorbidities, and those with long-standing asthma, achieved good control of asthma symptoms and normal lung function, although almost one-third had uncontrolled asthma despite receiving antiasthma therapy. The determinants of uncontrolled asthma were severe exacerbations during the preceding year, lack of adherence, and HRQOL. The presence of nonrespiratory comorbid conditions in older patients does not seem to be associated with worse control of asthma symptoms, although their influence on HRQOL could indirectly affect asthma control.

Therefore, the management of elderly asthmatic patients should include further care for clinical conditions, including depression, and adherence to treatment. The ACT and AQLQ questionnaires are complementary and highly informative.

\section{Funding}

The authors declare that no funding was received for the present study.

\section{Conflicts of Interest}

AEM has received lecture fees from Chiesi, AstraZeneca, Mundipharma, TEVA, and GSK. The remaining authors declare that they have no conflicts of interest.

\section{Previous Presentation}

Partial preliminary results from this study were presented orally at the XXX Spanish Allergy and Clinical Immunology Society Meeting (SEAIC) held in San Sebastian, Spain, 2016. 


\section{References}

1. Yáñez A, Cho SH, Soriano JB, Rosenwasser LJ, Rodrigo GJ Rabe KF, et al. Asthma in the elderly: what we know and what we have yet to know. World Allergy Organ J. 2014;30:7(1):8.

2. Enright PL, McClelland RL, Newman AB, Gottlieb DJ, Lebowitz MD. Underdiagnosis and undertreatment of asthma in the elderly. Cardiovascular Health Study Research Group. Chest. 1999;116(3):603-13.

3. Stupka E, deShazo R. Asthma in seniors: Part 1. Evidence for underdiagnosis, undertreatment, and increasing morbidity and mortality. Am J Med. 2009;122(1):6-11.

4. Boulet LP. Influence of comorbid conditions on asthma. Eur Respir J. 2009;33(4):897-906.

5. Baptist AP, Deol BB, Reddy RC, Nelson B, Clark NM. Agespecific factors influencing asthma management by older adults. Qual Health Res. 2010;20(1):117-24.

6. Jones SC, Iverson D, Burns P, Evers U, Caputi P, Morgan S. Asthma and ageing: an end user's perspective--the perception and problems with the management of asthma in the elderly. Clin Exp Allergy. 2011;41(4):471-81.

7. Braman SS. Growing old with asthma: what are the changes and challenges? Expert Rev Respir Med. 2010;4(2):239-48.

8. Adams RJ, Wilson DH, Taylor AW, Daly A, Tursan d'Espaignet E, Dal Grande E, et al. Coexistent chronic conditions and asthma quality of life: a population-based study. Chest. 2006;129(2):285-91.

9. Wijnhoven HA, Kriegsman DM, Hesselink $A E$, de Haan $M$, Schellevis FG. The influence of co-morbidity on health-related quality of life in asthma and COPD patients. Respir Med. 2003;97(5):468-75.

10. Dyer CA, Hill SL, Stockley RA, Sinclair AJ. Quality of life in elderly subjects with a diagnostic label of asthma from general practice registers. Eur Respir J. 1999;14(1):39-45.

11. Smith AM, Villareal M, Bernstein DI, Swikert DJ. Asthma in the elderly: risk factors and impact on physical function. Ann Allergy Asthma Immunol. 2012;108(5):305-10.

12. Plaza V, Serra-Batlles J, Ferrer M, Morejón E. Quality of life and economic features in elderly asthmatics. Respiration. 2000;67(1):65-70.

13. Huss K, Naumann PL, Mason PJ, Nanda JP, Huss RW, Smith $\mathrm{CM}$, et al. Asthma severity, atopic status, allergen exposure and quality of life in elderly persons. Ann Allergy Asthma Immunol. 2001;86(5):524-30.

14. Oğuztürk $O$, Ekici $A$, Kara M, Ekici M, Arslan M, Iteginli A, et al. E. Psychological status and quality of life in elderly patients with asthma. Psychosomatics. 2005;46(1):41-6.

15. Krauskopf KA, Sofianou A, Goel MS, Wolf MS, Wilson EA, Martynenko ME, et al. Depressive symptoms, low adherence, and poor asthma outcomes in the elderly. J Asthma. 2013;50(3):260-6.

16. Papadopoulos NG, Agache I, Bavbek S, Bilo BM, Braido F, Cardona $V$, et al. Research needs in allergy: an EAACl position paper, in collaboration with EFA. Clin Transl Allergy. 2012;2(1):21.

17. Global Initiative for Asthma (GINA). 2006 revision. www. ginasthma.com

18. Miller MR, Hankinson J, Brusasco V, Burgos F, Casaburi R, Coates $A$, et al. ATS/ERS Task Force. Standardisation of spirometry. Eur Respir J. 2005;26:319-38.
19. Vega JM, Badia X, Badiola C, López-Viña A, Olaguíbel JM, Picado $C$, et al. Covalair Investigator Group. Validation of the Spanish version of the Asthma Control Test (ACT). J Asthma. 2007;44(10):867-72.

20. Nathan RA, Sorkness CA, Kosinski M, Schatz M, Li JT, Marcus $P$, et al. Development of the asthma control test: a survey for assessing asthma control. J Allergy Clin Immunol. 2004;113(1):59-65.

21. Perpiñá $M$, Belloch $A$, Pascual LM, de Diego A, Compte L. [The quality of life in asthma: an evaluation of the AQLQ questionnaire for its use on a Spanish population. Asthma Quality of Life Questionnaire]. Arch Bronconeumol. 1995:31(5):211-8.

22. Marks GB, Dunn SM, WoolcockAJ. A scale for the measurement of quality of life in adults with asthma. J Clin Epidemiol. 1992;45(5):461-72.

23. Demoly P, Gueron B, Annunziata K, Adamek L, Walters RD. Update on asthma control in five European countries: results of a 2008 survey. Eur Respir Rev. 2010;19(116):150-7.

24. Cazzoletti L, Marcon A, Janson C, Corsico A, Jarvis D, Pin I, et al. Therapy and Health Economics Group of the European Community Respiratory Health Survey. Asthma control in Europe: a real-world evaluation based on an international populationbased study. J Allergy Clin Immunol. 2007;120(6):1360-7.

25. Price $D$, Fletcher $M$, van der Molen T. Asthma control and management in 8,000 European patients: the REcognise Asthma and LInk to Symptoms and Experience (REALISE) survey. NPJ Prim Care Respir Med. 2014;12;24:14009.

26. Ojeda P, Sanz de Burgoa V; Coste Asma Study. Costs associated with workdays lost and utilization of health care resources because of asthma in daily clinical practice in Spain. J Investig Allergol Clin Immunol. 2013;23(4):234-41.

27. Braido F, Brusselle $G$, Guastalla D, Ingrassia E, Nicolini $G$, Price D, et al. LIAISON Study Group. Determinants and impact of suboptimal asthma control in Europe: The INTERNATIONAL CROSS-SECTIONAL AND LONGITUDINAL ASSESSMENT ON ASTHMA CONTROL (LIAISON) study. Respir Res. 2016;14;17(1):51

28. Milanese M, Di Marco F, Corsico AG, Rolla G, Sposato B, Chieco-Bianchi F, et al. ELSA Study Group. Asthma control in elderly asthmatics. An Italian observational study. Respir Med.2014;108(8):1091-9.

29. Hwang EK, Jin HJ, Nam YH, Shin YS, Ye YM, Nahm DH, Park HS The predictors of poorly controlled asthma in elderly. Allergy Asthma Immunol Res. 2012 Sep;4(5):270-6.

30. Marincu I, Frent S, Tomescu MC, Mihaicuta S. Rates and predictors of uncontrolled bronchial asthma in elderly patients from western Romania. Clin Interv Aging. 2015;16(10):963-7.

31. Ban GY, Trinh TH, Ye YM, Park HS. Predictors of asthma control in elderly patients. Curr Opin Allergy Clin Immunol. 2016;16(3):237-43.

32. Yıldız F; ASIT Study Group. Factors influencing asthma control: of a real-life prospective observational asthma inhaler treatment (ASIT) study. J Asthma Allergy. 2013;1(6):93-101.

33. Ban GY, Ye YM, Lee Y, Kim JE, Nam YH, Lee SK, et al. Premier Researchers Aiming New Era in Asthma and Allergic Diseases (PRANA) Study Group. Predictors of Asthma Control by Stepwise Treatment in Elderly Asthmatic Patients. J Korean Med Sci. 2015;30(8):1042-7. 
34. Wardzyńska A, Kubsik B, Kowalski ML. Comorbidities in elderly patients with asthma: Association with control of the disease and concomitant treatment. Geriatr Gerontol Int. 2015;15(7):902-9.

35. Peters D, Chen C, Markson LE, Allen-Ramey FC, Vollmer WM. Using an asthma control questionnaire and administrative data to predict health-care utilization. Chest. 2006;129:91824.

36. Price D, Wilson M, Chisholm A, Rigazio A, Burden A, Thomas $M$, et al. Predicting frequent asthma exacerbations using blood eosinophil count and other patient data routinely available in clinical practice. J Asthma Allergy. 2016;9:1-12.

37. Demoly P, Paggiaro P, Plaza V, Bolge SC, Kannan H, Sohier $B$, et al. Prevalence of asthma control among adults in France, Germany, Italy, Spain and the UK. Eur Respir Rev. 2009;(112):105-12.

38. Luskin AT, Chipps BE, Rasouliyan L, Miller DP, Haselkorn T, Dorenbaum A. Impact of asthma exacerbations and asthma triggers on asthma-related quality of life in patients with severe or difficult-to-treat asthma. J Allergy Clin Immunol Pract. 2014;2(5):544-52.
39. Park HW, Kim TW, Song WJ, Kim SH, Park HK, Kim SH, et al. Prediction of asthma exacerbation in elderly adults: results of a 1-year prospective study. J Am Geriatr Soc. 2013:61;1631-2.

Manuscript received February 13, 2019; accepted for publication June 24, 2019.

\section{- Alicia Enríquez-Matas}

Servicio de Alergología, Hospital Universitario 12 de Octubre

Instituto de Investigación Hospital 12 de Octubre (i+12)

Edificio CAA, planta $4^{\circ}$ bloque D

Avda Córdoba s/n

28041 Madrid, Spain

E-mail: alicia.enriquez@salud.madrid.org 